\title{
Severe Maternal Outcomes and Quality of Maternal Health Care in South Ethiopia
}

\author{
Tesfalidet Beyene $\mathbb{D}^{1,2}$, Catherine Chojenta $\mathbb{D}^{3}$, Roger Smith ${ }^{4}$, Deborah Loxton ${ }^{3}$ \\ 'Priority Research Centre for Healthy Lungs, University of Newcastle, Newcastle, NSW, Australia; ${ }^{2}$ College of Medicine and Health Sciences, Wollega \\ University, Nekemte, Oromia, Ethiopia; ${ }^{3}$ Centre for Women's Health Research, University of Newcastle, Newcastle, NSW, Australia; ${ }^{4}$ The Mothers
} and Babies Research Centre at the Hunter Medical Research Institute, University of Newcastle, Newcastle, NSW, Australia

Correspondence: Tesfalidet Beyene, Email ttesfalove@gmail.com

Objective: To assess the incidence of severe maternal outcomes (SMO) and quality of maternal health care in south Ethiopia. Methods: A facility-based prospective study was conducted in three hospitals among all women who presented while pregnant, during and after childbirth between 12 July and 26 November 2018. Participants were followed from the time of admission to discharge. The World Health Organization (WHO) maternal near-miss (MNM) approach was used to assess SMO indicators and quality of maternal health care.

Results: Of 2880 live births, 315 had potentially life-threatening conditions and 108 had SMOs (90 MNM and 18 maternal deaths). The SMO incidence ratio was 37.5 per 1000 live births (95\% CI 30.6-44.4) and MNM incidence ratio was 31.3 per 1000 live births (95\% CI 24.9-37.7). The ratio of near-miss to maternal deaths was 5:1. The hospitals' maternal mortality ratio (MMR) was 625 per 100,000 live births. Most (82.1\%) SMO cases were referred from other health facilities. The most common cause of SMO was eclampsia (37\%) followed by postpartum haemorrhage (33.3\%). The highest mortality index (MI) was among women with sepsis (27.3\%). The intensive care unit (ICU) admission rate was $13 \%$ for women with SMO and $83.3 \%$ of maternal deaths occurred without ICU admission.

Conclusion: The SMO ratio was comparable to other studies in the country. Most women with SMO were referred from other health facilities, which demonstrate the presence of the first delay (seeking care) and/or the second delay (reaching care) in the study area. The study suggests that effectively using the ICU, reducing delays, and improving the referral system may reduce SMO and improve the quality of care in the hospitals. Furthermore, continuous reviewing of SMO is needed to learn what treatment was given to women who experienced complications in the hospitals.

Keywords: maternal near miss, maternal deaths, severe maternal outcomes, Ethiopia

\section{Introduction}

According to WHO reports, globally, the MMR reduced by 44\% from 385 deaths per 100,000 live births in 1990 to 216 deaths per 100,000 live births in 2015. Nearly $99 \%$ of these deaths occurred in low-income countries, with sub-Saharan Africa and Southern Asia alone accounting for more than half of maternal deaths. ${ }^{1}$ The WHO target is an average global MMR of fewer than 70 deaths per 100,000 live births by 2030; moreover, at the country level, no country should have an MMR higher than 140 deaths per 100,000 live births by $2030 .^{2}$ Maternal mortality accounts for only a small percentage of the overall burden of maternal health problems. ${ }^{3-5}$ Many women who experience life-threatening complications may die, and a proportion may narrowly escape death due to a lifesaving obstetric intervention. ${ }^{6,7}$ For every mother who dies due to pregnancy-related complications, 20 to 30 mothers develop severe life-threatening complications that influence the life of the mother physically and psychologically., ${ }^{4,5,8-10}$

Previously, various criteria were used to describe near miss. ${ }^{11}$ However, in 2011, the WHO developed new MNM criteria. $^{7}$ Based on these criteria, MNM is defined as, "a woman who nearly died but survived a complication that occurred during pregnancy, childbirth or within 42 days of termination of pregnancy". 7,12 Women are considered to have experienced MNM when they survive organ dysfunction. Organ dysfunction criteria reflect severe morbidity and are 
important for identification of MNM. For example, obstetric haemorrhage constitutes MNM through respiratory dysfunction (acute cyanosis, gasping, severe tachypnoea) or cardiovascular dysfunction (hypovolemia, shock and circulatory collapse). ${ }^{7,12}$ Studying MNM is recognized as an appropriate method for assessing the quality of maternal health care and ascertaining how many women need obstetric care during pregnancy, childbirth and the postnatal period. Women who survive MNM have many characteristics in common with those who die of life-threatening complications. ${ }^{7,13,14}$ Quality of maternal health can be assessed using either outcome indicators such as SMO or MNM or by using process indicators like use of magnesium sulphate for treatment of eclampsia or use of parenteral antibiotics for treatment of sepsis. ${ }^{7}$

Recently, there has been progress in the reduction of maternal deaths in Ethiopia. ${ }^{1,15,16}$ The 2016 Ethiopian Demographic and Health Survey (EDHS) reported 412 maternal deaths per 100,000 live births. ${ }^{16}$ This may have resulted from government commitments to increasing health services and community health workers in the country. In 2014, the Ministry of Health developed a maternal death review as one of the strategies to reduce the high rate of maternal deaths in the country. This review system recommends that all maternal deaths and MNMs be reviewed in hospital facilities. ${ }^{17}$ A few published studies in Ethiopia addressing MNM have used the WHO criteria as the definition of MNM. ${ }^{18-20}$ However, there has only been one case-control study conducted in south Ethiopia; ${ }^{21}$ this study used a disease-specific approach and as a result, may have over-reported MNM cases. The disease-specific approach has five diagnostic criteria: severe postpartum haemorrhage, uterine rupture, hypertensive disorders, infection and abortion. MNM occurs more frequently, thereby allowing for the identification of more cases and providing the opportunity to interview the women who survived. ${ }^{7}$ Assessment of how frequently SMO occurred provides an estimate of the quality of care. For instance, more than 10 SMOs per 1000 live births show that numerous women experiencing complications will require lifesaving interventions to survive. ${ }^{7}$ Therefore, the objective of this study is to identify the incidence of SMO and process indicators related to quality of maternal health care in south Ethiopia.

\section{Methods}

\section{Study Settings}

The study was conducted in three selected hospitals in the Southern Nations, Nationalities and Peoples' Region (SNNPR). The region is located in the south of Ethiopia. Hawassa, which is 285 kilometres from Addis Ababa, is the capital city of the region. According to the Central Statistical Agency (CSA) report, the region has a total population of 15 million, of whom half $(50.3 \%)$ are women. ${ }^{22}$ The hospitals selected for the study were Hawassa University Comprehensive Specialized Hospital (HUCSH), Nigist Eleni Mohammed General Hospital (NEMGH) and Durame General Hospital (DGH). HUCSH is a teaching referral hospital ranked in the top level of the three-tier Ethiopian health care system. HUCSH provides services to a catchment population from the SNNPR and other neighbouring catchments of the Oromia region. NEMGH is a general hospital located in Hosanna city that provides services to a catchment population of $1,506,733$. The DGH is located in Durame city and serves as a referral hospital for Kembata Tembaro zone.

\section{Study Design and Period}

This was a prospective cohort study involving pregnant women who were admitted for delivery or pregnancy-related complications between 12 July and 26 November 2018.

\section{Sample Size}

The sample size calculation for the current study has been indicated elsewhere. ${ }^{23}$

\section{Study Population}

The study population consisted of all women admitted to the selected hospitals during pregnancy, childbirth or within 42 days of pregnancy termination during the study period. Eligibility for the study was not restricted by gestational age. Women who experienced complications more than 42 days after delivery were not eligible. 


\section{Data Collection Tool and Techniques}

The data collection tool was based on the WHO near-miss approach. ${ }^{7}$ The tool was prepared using an online survey application (Survey Gizmo) and downloaded on iPads for offline data collection. Three trained data collectors were recruited to collect the data, which were collected on a daily basis. The data collectors were health care providers who were not staff of the hospitals. Participants' medical records and charts were reviewed until participants were discharged from the hospital. The data collectors made day-to-day visits to delivery rooms, obstetric wards, maternity waiting rooms, gynaecology wards and ICUs to obtain pertinent data related to pregnancy complications and pregnancy outcomes. In uncertain cases or cases of missing data on medical records, the data collectors contacted attending health care providers to obtain more information. Data were collected regarding morbidities, contributory or associated conditions, and treatment and management of complications. Morbidities were defined according to potentially lifethreatening conditions such as sepsis, severe postpartum haemorrhage, uterine rupture, severe pre-eclampsia, eclampsia and abortion. Key clinical, laboratory and management criteria were used to identify women who developed lifethreatening conditions (see Table 1).

Data were collected on obstetric care interventions used for the prevention and management of the causes of complications. Further, associated or contributory conditions related to SMO were extracted from the medical records. Access to hospital and intrahospital care was evaluated according to the proportion of women with SMO presenting within the first 12 hours of hospital stay or after 12 hours of hospital stay. Based on WHO criteria, the latter indicated the quality of care provided within the hospital. ${ }^{7}$ The quality was assessed based on the actual use and optimal use of effective lifesaving interventions in the prevention and management of severe complications after the women arrived in hospital. Information about referral status was also collected. Referred cases signified women coming from other health facilities and was a good indicator of the hospital referral system. The supervisors were health care providers who were employed by study team to oversee the data collection process by checking the collected data and providing feedback. The supervisors were not staff of the hospitals.

\section{Data Processing and Analysis}

The data were exported from the Survey Gizmo application into SPSS Statistics 20 for analysis. Descriptive statistics of indicators of MNM and process indicators were calculated. Severe maternal outcome ratio, maternal near-miss ratio (MNMR), MI and MMR were calculated (see Table 2). The results were presented in accordance with the WHO MNM approach, using clinical, laboratory and management criteria. ${ }^{7}$ The definitions for MNM terminology and indicators were taken from the WHO near-miss approach and published research. ${ }^{7,12}$

\section{Ethical Considerations}

This study was conducted in accordance with the Declaration of Helsinki. Ethical approval was granted from the Human Research Ethics Committee (HREC) of the University of Newcastle, Australia (reference no. H-2017-0253; date: 15-Jun -2018) and Institutional Review Board located in SNNPR Health Bureau, Ethiopia (reference no.pm 37-186/24015). Informed verbal consent was obtained from each participant before conducting the interviews. The ethics committees had approved the verbal consent procedure.

\section{Results}

A total of 3010 women presented during the study period. Three thousand and six women agreed to participate in the study. Three hundred and fifteen women developed potentially life-threatening conditions and 108 experienced SMO (90 near misses and 18 maternal deaths) (Figure 1). The SMO and MNM incidence ratios were 37.5 (95\% CI $=30.6-44.4$ ) and $31.3(95 \% \mathrm{CI}=24.9-37.7)$ per 1000 live births, respectively. The hospital-based MMR was 625 per 100,000 live births with an MI of $16.7 \%$. 
Table I WHO Near-Miss Criteria and Modifications for South Ethiopia, 2018

\begin{tabular}{|c|c|}
\hline WHO Near-Miss Criteria & South Ethiopia \\
\hline \multicolumn{2}{|l|}{ Clinical criteria } \\
\hline Acute Cyanosis & Not modified \\
\hline Gasping & Not modified \\
\hline Respiratory rate $>40$ or $<6 / \mathrm{min}$ & Not modified \\
\hline Shock & Not modified \\
\hline Oliguria nonresponsive to fluids or diuretics & Not modified \\
\hline Failure to form clots & Not modified \\
\hline Loss of consciousness lasting $\geq 12 \mathrm{hrs}$ & Not modified \\
\hline Cardiac arrest & Not modified \\
\hline Stroke & Not modified \\
\hline Uncontrollable fit/total paralysis & Not modified \\
\hline Jaundice in the presence of pre-eclampsia & Not modified \\
\hline \multicolumn{2}{|l|}{ Laboratory-based criteria } \\
\hline Acute thrombocytopenia $(<50,000$ platelets $/ \mathrm{mL})$ & Not modified \\
\hline $\mathrm{PaO} 2 / \mathrm{FiO} 2<200 \mathrm{mmHg}$ & Not available \\
\hline Creatinine $\geq 300 \mathrm{mmol} / \mathrm{l}$ or $\geq 3.5 \mathrm{mg} / \mathrm{dL}$ & Not modified \\
\hline Ketoacidosis in urine & Not available \\
\hline Oxygen saturation $<90 \%$ for $\geq 60 \mathrm{~min}$ & Not modified \\
\hline Lactate $>5 \mathrm{mmol} / \mathrm{L}$ & Not available \\
\hline \multicolumn{2}{|l|}{ Management-based criteria } \\
\hline Admission to intensive care unit & Not modified \\
\hline Use of continuous vasoactive drugs & Not modified \\
\hline Haemorrhage or infection leading to hysterectomy & Not modified \\
\hline Transfusion of $\geq 5$ units of blood* & Modified \\
\hline Intubation and ventilation for $\geq 60 \mathrm{~min}$ not related to anesthesia & Not modified \\
\hline Dialysis for acute renal failure & Not available \\
\hline Cardio-pulmonary resuscitation & Not modified \\
\hline
\end{tabular}

Notes: *Transfusion of $\geq 2$ units of blood. WHO near-miss criteria data from: World Health Organization. Evaluating the quality of care for severe pregnancy complications: the WHO near-miss approach for maternal health; 20II. Available from: https://apps.who.int/iris/bitstream/handle/I0665/44692/978924I50222I_eng.pdf? sequence $=\mid$ \&isAllowed $={ }^{7}{ }^{7}$

\section{Underlying Causes for Severe Maternal Outcomes}

Morbidities are classified according to the underlying cause and contributory condition in Table 3 . The leading causes of MNM were severe postpartum haemorrhage (34.4\%) and eclampsia (34.4\%). Eclampsia (50\%) was the leading cause of maternal death. Sepsis $(27.3 \%)$ had the highest MI. Anaemia was the leading contributory factor for both MNM and maternal death. 
Table 2 Maternal Near-Miss Definitions and Indicators

\begin{tabular}{|c|c|}
\hline Terminology & Definitions \\
\hline \multicolumn{2}{|l|}{ Near-miss indicators } \\
\hline Maternal near miss (MNM) & $\begin{array}{l}\text { A woman who nearly died but survived a complication that occurred during pregnancy, childbirth or within } \\
42 \text { days of termination of pregnancy }\end{array}$ \\
\hline MNM ratio (MNMR) & The number of maternal near-miss cases per 1000 live births \\
\hline Maternal mortality ratio (MMR) & The number of maternal deaths per 100,000 live births \\
\hline Severe maternal outcome (SMO) & The sum of maternal near misses and maternal deaths \\
\hline $\begin{array}{l}\text { Severe maternal outcome ratio } \\
\text { (SMOR) }\end{array}$ & $\begin{array}{l}\text { The number of women with SMO per } 1000 \text { live births (LB). This indicator gives an estimate of the amount of } \\
\text { care and resources that would be needed in an area or facility }\end{array}$ \\
\hline $\begin{array}{l}\text { Maternal near-miss mortality ratio } \\
\text { (MNM: I MD) }\end{array}$ & The ratio between maternal near miss and maternal deaths. Higher ratios show better care \\
\hline Mortality index & $\begin{array}{l}\text { The number of maternal deaths divided by the number of women with SMO. The lower the index, the fewer } \\
\text { women with life-threatening complications die (better quality of care) whereas the higher the index, the } \\
\text { more women with life-threatening complications die (low quality of care) }\end{array}$ \\
\hline \multicolumn{2}{|l|}{ Hospital access indicators } \\
\hline SMOI2 & $\begin{array}{l}\text { Women presenting the organ dysfunction or maternal death (SMO) within } 12 \text { hours of hospital stay from } \\
\text { admission }\end{array}$ \\
\hline SMOI 2 mortality index & The number of women with SMOI 2 divided by the number of all SMO cases expressed as a percentage \\
\hline \multicolumn{2}{|l|}{ Intrahospital access indicators } \\
\hline SMO after 12 hrs of hospital stay 12 & Women experienced SMO after 12 hours of hospital stay \\
\hline SMO after 12 hrs mortality index & $\begin{array}{l}\text { The number of women with SMO after } 12 \text { hours of hospital stay divided by the number of all SMO cases } \\
\text { expressed as a percentage }\end{array}$ \\
\hline \multicolumn{2}{|l|}{ Process indicators } \\
\hline $\begin{array}{l}\text { Prevention of postpartum } \\
\text { haemorrhage }\end{array}$ & $\begin{array}{l}\text { The number of women who received a single dose of oxytocin divided by the number of all women giving } \\
\text { birth }\end{array}$ \\
\hline $\begin{array}{l}\text { Treatment of severe postpartum } \\
\text { haemorrhage }\end{array}$ & $\begin{array}{l}\text { The number of women with severe PPH who received therapeutic oxytocin divided by the number of all } \\
\text { women with postpartum haemorrhage. }\end{array}$ \\
\hline Treatment sepsis & $\begin{array}{l}\text { The number of women with sepsis who received IV antibiotics divided by the number of all women with } \\
\text { sepsis }\end{array}$ \\
\hline
\end{tabular}

The most common organ dysfunctions among women with MNM were cardiovascular dysfunction (53.3\%), followed by respiratory dysfunction (48.9\%), whereas neurologic dysfunction $(72.2 \%)$ was the most common dysfunction among maternal deaths. The MNM mortality ratio was highest for respiratory dysfunction, (11:1) followed by cardiovascular dysfunction (6:1). The MI was highest for neurologic dysfunction (40.6\%). The most critical intervention administered to women who experienced SMO was blood products (Table 4).

\section{Facility-Related Indicators}

The majority (87.9\%) of women with SMO presented with life-threatening conditions on arrival or within the first 12 hours of hospital admission; $82.1 \%$ of these came from other health facilities. The MI of women with SMO on arrival or within the first 12 hours of hospital admission was 13.7\%. Thirteen women developed SMO after 12 hours of hospital 


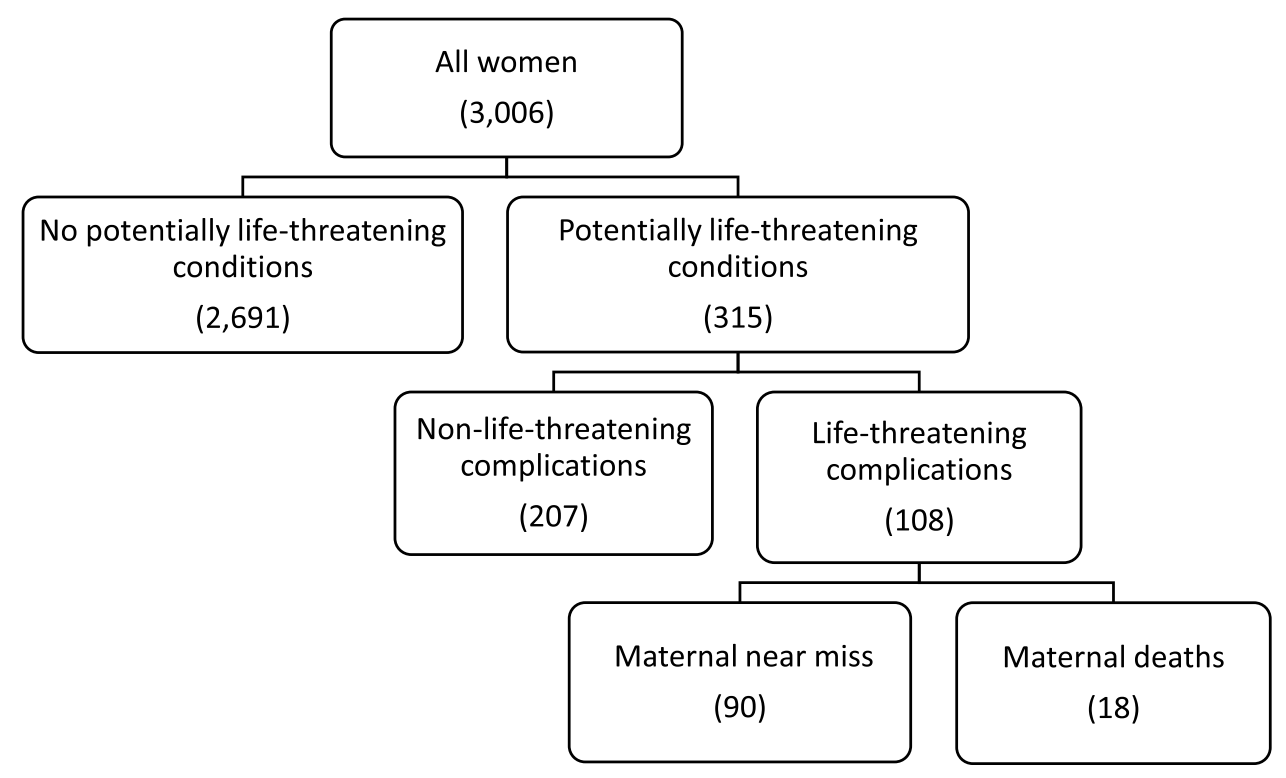

Figure I Study flowchart of severe maternal outcomes in south Ethiopia, 2018.

admission and five of these died. The ICU admission rate was $0.5 \%$, while the ICU admission rate among women with SMO was $13 \%$. The majority (83.3\%) of maternal deaths occurred without ICU admission (Table 5).

\section{Use of Intervention and Treatment}

Almost all (99.1\%) women received oxytocin for prevention of postpartum haemorrhage, while $81.7 \%$ of the women with severe postpartum haemorrhage received oxytocin for treatment of that complication. Most women with eclampsia

Table 3 Morbidity Conditions and Contributory Causes Among Women with Severe Maternal Outcomes in South Ethiopia, 2018

\begin{tabular}{|c|c|c|c|c|}
\hline Morbidity & MNM N (\%) & Maternal Deaths N (\%) & MNM Mortality Ratio & Mortality Index \\
\hline Severe postpartum haemorrhage & $31(34.4)$ & $5(27.8)$ & $6: 1$ & 13.8 \\
\hline Severe pre-eclampsia & $16(17.8)$ & $2(11.1)$ & $8: 1$ & II.I \\
\hline Eclampsia & $31(34.4)$ & $9(50)$ & $4: 1$ & 22 \\
\hline Sepsis or severe systemic infection & $8(8.9)$ & $3(16.7)$ & $3: 1$ & 27.3 \\
\hline Uterine rupture & $9(10)$ & $2(I I .1)$ & $5: 1$ & 18.2 \\
\hline Pregnancy with abortive outcome (abortion/ectopic pregnancy) & $4(4.4)$ & $0(0)$ & - & - \\
\hline \multicolumn{5}{|l|}{ Contributory causes/associated conditions } \\
\hline Anaemia & $49(54.4)$ & $9(50)$ & $5: 1$ & 15.5 \\
\hline HIV infection & $\mathrm{I}(\mathrm{I} .1)$ & I (5.6) & $1: 1$ & 50 \\
\hline Previous caesarean section & $10(11.1)$ & $2(11.1)$ & $5: 1$ & 16.6 \\
\hline Prolonged/obstructed labour & $15(16.7)$ & $6(33.3)$ & $3: 1$ & 28.6 \\
\hline Malaria & $7(7.8)$ & $3(16.7)$ & $2: 1$ & 30 \\
\hline TB & $\mathrm{I}(\mathrm{I.1})$ & $0(0)$ & - & - \\
\hline No contributory cause & $15(16.7)$ & $2(11.1)$ & $8: 1$ & 11.8 \\
\hline Others & $8(8.9)$ & I (5.5) & $8: 1$ & 12.5 \\
\hline
\end{tabular}


Table 4 Frequencies of Severe Maternal Outcomes by Type of Organ System Dysfunction and Critical Intervention in South Ethiopia, 2018

\begin{tabular}{|c|c|c|c|c|}
\hline Organ Dysfunctions & MNM Cases N (\%) & Maternal Death N (\%) & MNM Mortality Ratio & Mortality Index (\%) \\
\hline Cardiovascular & $48(53.3)$ & $8(44.4)$ & $6: 1$ & 14.2 \\
\hline Renal & $2(2.2)$ & I (5.6) & $2: 1$ & 33.3 \\
\hline Respiratory & 44 (48.9) & $4(22.2)$ & II:I & 8.3 \\
\hline Hepatic & $3(3.3)$ & $2(I I . I)$ & $2: 1$ & 40 \\
\hline Neurologic & $19(21.1)$ & $13(72.2)$ & $2: 1$ & 40.6 \\
\hline Hematologic & $19(21.1)$ & $4(22.2)$ & $5: 1$ & 17.4 \\
\hline Hysterectomy/uterine & $8(8.9)$ & $2(I I . I)$ & $4: 1$ & 20 \\
\hline Multiple organ & $36(40 \%)$ & $12(66.7)$ & $3: 1$ & 25 \\
\hline \multicolumn{5}{|l|}{ Critical intervention } \\
\hline Use of blood products & $25(27.8)$ & 7 (38.9) & $4: 1$ & 21.9 \\
\hline Interventional radiology & $0(0)$ & $0(0)$ & - & - \\
\hline Laparotomy other than CS & $13(14.4)$ & $2(I I . I)$ & $7: 1$ & 13.3 \\
\hline Admission to intensive care unit & II (I2.6) & $3(16.7)$ & $4: 1$ & 21.4 \\
\hline
\end{tabular}

(95.1\%) received magnesium sulphate. Prophylactic antibiotics were given to $94.1 \%$ of all women who underwent a caesarean section. Three-quarters (75\%) of women with sepsis received parenteral antibiotics (Table 6).

\section{Discussion}

In this study, the incidence of SMO was 37.5 per 1000 live births $(95 \% \mathrm{CI}=30.6-44.4)$ within the surveyed hospitals and the use of lifesaving interventions, such as the use of antibiotics to treat women with sepsis, was suboptimal. The majority of women with SMO developed organ dysfunction before or within the first 12 hours of hospital arrival. Moreover, ICU admission of women with SMO was $13 \%$.

The study showed that SMO and MNM incidence ratios were 37.5 and 31.3 per 1000 live births at the hospitals, respectively. According to a recent WHO report, an MNM or SMO ratio higher than 10 per 1000 live births indicates that a large percentage of women will need lifesaving interventions to survive their complications. ${ }^{7}$ The current study underscores the frequent occurrence of SMO in the study area.

MNM is a newly accepted tool for identifying women at the utmost risk of maternal death. It helps to guide allocation of resources to women who are at the greatest risk of death. ${ }^{7}$ The MNMR found in this study is higher than in other study conducted in Ethiopia, which have reported 8.01 per 1000 live births. ${ }^{20}$ The observed difference may be because the present study used the modified WHO criteria to identify MNM. Conversely, the results are lower than studies conducted in south-west Ethiopia (50.4 per 1000 live births) and east Ethiopia (80 per 1000 live births). ${ }^{18,19}$ The reason for this difference may be that the study in south-west Ethiopia included only one tertiary (higher) hospital, where the majority of severe complications were found. However, the MNMR of this study is comparable with other studies conducted in Africa, which have reported incidences of MNM ranging from 28.6 to 36 per 1000 live births. ${ }^{24,25}$

The MMR in this study was 625 per 100,000 live births, which is higher than the national report of 412 per 100,000 live births ${ }^{16}$ but a notable reduction from 676 per 100,000 live births at the national level. ${ }^{15}$ This may reflect the effect of referral of the most serious cases from other areas and that some women from the catchment regions delivered outside of the hospitals. Reduction of MMR at the national level may be due to the expansion of maternity health care services and increased resource allocation. The higher MMR found in the present study compared to the current national level may be explained by the fact that the national report data were collected at the community level but not from health facilities; 
Table 5 Severe Maternal Outcomes, Near-Miss Indicators and Facility-Related Indicators in South Ethiopia, 20I8

\begin{tabular}{|c|c|}
\hline Maternal Outcomes and Indicators & Value \\
\hline All live births in the population under surveillance & 2880 \\
\hline Severe maternal outcome (SMO) cases (number) & 108 \\
\hline Maternal deaths & 18 \\
\hline Maternal near-miss cases & 90 \\
\hline \multicolumn{2}{|l|}{ Overall near-miss indicators } \\
\hline Severe maternal outcome ratio (per 1000 live births) & 37.5 \\
\hline Maternal near-miss incidence ratio (per 1000 live births) & 31.3 \\
\hline Maternal mortality ratio per 100,000 live births & 625 \\
\hline Maternal near-miss mortality ratio & $5: 1$ \\
\hline Mortality index & 16.7 \\
\hline \multicolumn{2}{|l|}{ Hospital access indicators } \\
\hline SMO cases identified on arrival or within $12 \mathrm{hrs}$ of hospital stay & 95 \\
\hline Mothers who died on arrival or within I $2 \mathrm{hrs}$ of hospital stay & 13 \\
\hline Percentage of SMOI2 cases among all SMO cases & 87.9 \\
\hline $\begin{array}{l}\text { Women with SMO cases at arrival or within } 12 \text { hrs of hospital arrival and coming from other health } \\
\text { facilities }\end{array}$ & 78 \\
\hline Percentage of SMOI2 cases coming from other health facilities & 82.1 \\
\hline SMOI 2 mortality index & 13.7 \\
\hline \multicolumn{2}{|l|}{ Intra-hospital care } \\
\hline Intra-hospital SMO cases of organ dysfunction or maternal death after $12 \mathrm{hrs}$ of hospital stay & 13 \\
\hline Rate of intra-hospital SMO (per 1000 live births) & 4.5 \\
\hline Women with SMO developed after $12 \mathrm{hrs}$ of hospital arrival who died & 5 \\
\hline Intra-hospital mortality index & 38.4 \\
\hline \multicolumn{2}{|l|}{ Intensive care Unit used } \\
\hline Total number of women & 3006 \\
\hline Percentage of ICU admission & $0.5 \%$ \\
\hline Percentage of ICU admission among women with SMO & $13 \%$ \\
\hline Percentage of maternal deaths occurred without ICU admission & 83.3 \\
\hline
\end{tabular}

more women come to health facilities after developing complications, which may result in more deaths. The MMR of this study is lower than that identified in other studies conducted in Ethiopia and Ghana: 876.9 and 1154 per 100,000 live births, respectively. ${ }^{18,25}$ The lower ratio in the present study may be explained by the fact that the study included two general hospitals where women with less severe complications than those in other hospitals were admitted. However, the MMRs in the present study were almost equal to those in a previous study undertaken in four regions of Ethiopia, which reported 633 per 100,000 live births. ${ }^{26}$ 
Table 6 Use of Interventions for Prevention and Treatment of Major Obstetric Complications in South Ethiopia, 2018

\begin{tabular}{|c|c|}
\hline Interventions & $\mathbf{N}(\%)$ \\
\hline \multicolumn{2}{|l|}{ Prevention of PPH } \\
\hline Target population: women giving birth in health facilities & 2935 \\
\hline Oxytocin & $2910(99.1)$ \\
\hline \multicolumn{2}{|l|}{ Treatment of severe PPH } \\
\hline Target population: women with severe PPH & 82 \\
\hline Oxytocin & $67(81.7)$ \\
\hline Ergometrine & $13(15.9)$ \\
\hline Other uterotonics & $0(0)$ \\
\hline Tranexamic acid & $0(0)$ \\
\hline Removal of retained products & $12(14.6)$ \\
\hline Balloon or condom tamponade & $0(0)$ \\
\hline Artery ligation (uterine/hypogastric) & $0(0)$ \\
\hline Hysterectomy & $3(3.6)$ \\
\hline Abdominal packing & $4(4.9)$ \\
\hline Cases with SMO & $36(43.9)$ \\
\hline Mortality & $5(6.1)$ \\
\hline \multicolumn{2}{|l|}{ Anticonvulsants for eclampsia } \\
\hline Target population: women with eclampsia & 61 \\
\hline Magnesium sulphate & $58(95.1)$ \\
\hline Other anticonvulsant & $5(8.2)$ \\
\hline Cases with SMO & $40(65.6)$ \\
\hline Mortality & $9(14.8)$ \\
\hline \multicolumn{2}{|l|}{ Prevention of caesarean-related infection } \\
\hline Target population: women undergoing caesarean from PLTC & 119 \\
\hline Prophylactic antibiotic during caesarean & $112(94.1)$ \\
\hline \multicolumn{2}{|l|}{ Treatment for sepsis } \\
\hline Target population: women with sepsis including PLTC & 36 \\
\hline Parenteral therapeutic antibiotic & $27(75)$ \\
\hline Proportion of cases with SMO & II (30.5) \\
\hline Mortality & $3(8.3)$ \\
\hline
\end{tabular}

The current study showed a high MI (16.7\%), indicating that the quality of care provided to women with severe complications may need improvement. Similar studies from sub-Saharan Africa reported $10.6 \%$ to $28.2 \% \mathrm{MI},{ }^{18,25,27,28}$ compared to middle- and high-income countries which demonstrated a low MI of less than $10 \% .{ }^{29-31}$ These findings 
reveal that a large proportion of critically ill women in low-income countries die from severe complications and that the quality of maternal care delivered to women with complications must be reviewed. Studies have reported that even in resource-limited settings, SMO can be reduced by improving maternal health through the use of effective interventions and maternal death audits. ${ }^{32,33}$

The current study showed that the leading causes of SMO were eclampsia and severe postpartum haemorrhage, which are comparable to the findings of studies conducted elsewhere in Ethiopia ${ }^{18-20,26}$ and other African countries. ${ }^{10,25,27,34}$ In the current study, anaemia was found to be a major contributing cause to more than half of SMOs, which is higher than other population-based studies among women in the country. ${ }^{16,35,36}$ This difference may be explained by the vulnerable status of women with SMO compared with the general obstetric population. ${ }^{37}$

Unlike other studies in Ethiopia, ${ }^{18,19}$ the MI in this study is highest for those women with sepsis. The reason for this may be that in this study, only three-quarters of women who developed potentially life-threatening conditions received parenteral therapeutic antibiotics. This is comparable with a study undertaken in east Ethiopia that reported that only $79 \%$ of the women received parenteral antibiotics. ${ }^{19}$ One study conducted in South Africa indicated that a low MI reflects a reasonable quality of care, an efficient health system and clear protocols and guidelines for the prevention and management of obstetric complications. ${ }^{38}$ The findings of the present study suggest the need for improvement in caring for women who have developed sepsis.

In the current study, $87.9 \%$ of the women with SMO had organ dysfunction on admission or within the first 12 hours of arrival at the facility; the majority (82.1\%) of these were referred from other health facilities. According to the WHO, if a large proportion of women arrive at health facilities with SMO, this suggests a delay in seeking care or a delay in reaching a health care facility. ${ }^{7}$ This study's results suggest that the quality of care and the referral system in lower-level health facilities in the SNNPR are in need of attention. In addition, it is possible that numerous women with complications are kept in health facilities for too long before being referral. This finding is comparable with studies from Ethiopia ${ }^{18,19}$ and other African countries, ${ }^{24,25,34}$ which reported that the majority of women had SMO on admission or within the first 12 hours of arrival at hospitals, and the majority came from other health facilities after developing complications. Together, these findings indicate that there is an issue with delays in reaching the hospitals either because the women or their families are late in deciding to seek care or because the referral system in different levels of facility is weak. This highlights the influence of access and the referral system on women with SMO in low-resourced settings in which maternal mortality remains unacceptably high.

The current study's findings show that ICU admission rate among women with SMO was 13\% and the majority (83.3\%) of maternal deaths occurred without ICU admission. This low percentage of women with SMO admitted to the ICU and the high percentage of maternal deaths that occurred without ICU admission suggest a shortage of ICU beds for women with lifethreatening conditions. This is similar to the findings of studies in Ethiopia ${ }^{18}$ and other African countries. ${ }^{25,27,34}$ The current study demonstrates there is a need for greater ICU access in the obstetric population in the study area. Therefore, it is necessary to establish ICUs dedicated solely to the obstetric population. Further, ICU use must be revised, and high dependency units must be better equipped with adequate resources to improve pregnancy outcomes.

Appropriate use of effective interventions result in improved health outcomes. ${ }^{7,39}$ In this study, the use of uterotonic drugs to prevent and treat postpartum haemorrhage and the use of antibiotics for caesarean delivery was found to be high; however, only three-quarters of women with sepsis received parenteral treatment with antibiotics. This is comparable to another study examining SMO in east Ethiopia. ${ }^{19}$

The study has several strengths. This study has added to the literature by assessing interventions provided for women with SMO and hospital access indicators, which are essential components of quality of care. The use of prospective data to identify women with SMO and the quality of care provided to women with life-threatening conditions using a validated WHO tool is a further strength. ${ }^{7}$ However, the present study also has limitations; it was conducted in one tertiary and two general hospitals. Therefore, the findings may not be generalizable to all south Ethiopia. Another limitation is that the data were only collected until women were discharged from the hospitals and, as such, complications occurring after discharge until the postpartum period (42 days after childbirth) may have been missed. 


\section{Conclusion}

In the current study, most women with SMO developed organ dysfunction on arrival or within the first 12 hours of arrival to the hospital. Many of these women were referred from other health facilities, which showed the presence of the first and second delays in the study area. The study also demonstrated suboptimal use of evidence-based interventions for women experiencing SMO, such as parenteral antibiotics. Effective use of evidence-based life-saving maternal health care interventions, critical care, reducing delays and improving the referral system may reduce SMO and improve care in hospitals. Training of health care providers in regard to referring women with severe maternal complications is required. Moreover, continuous auditing of maternal complications is needed to learn from the way they are treated at different levels of the referral system.

\section{Future Research}

Future longitudinal studies are required to identify SMO using the WHO MNM approach including women in the postpartum period (from birth until 42 days after birth). Qualitative research interviewing women with MNM is also needed as this may help to reveal barriers to receiving hospital care and identify delays.

\section{Abbreviations}

CI, confidence interval; MI, mortality index; MMR, maternal mortality ratio; MNM, maternal near miss; MNMR, maternal near-miss ratio; SMO, severe maternal outcomes.

\section{Acknowledgments}

We would like to acknowledge the University of Newcastle, Australia, for funding TB's higher degree research and financing the research undertaking. We also want to thank the administrators of the hospitals and all staff working in the maternity unit who helped during the data collection period. Finally, we thank Natalia Soeters for language and grammar editing.

\section{Disclosure}

The authors declare that they have no conflicts of interest for this work.

\section{References}

1. World Health Organization. Trends in Maternal Mortality: 1990 to 2015: Estimates by WHO, UNICEF, UNFPA, World Bank Group and the United Nations Population Division. Geneva: World Health Organization; 2015.

2. World Health Organization. Strategies toward ending preventable maternal mortality (EPMM); 2015.

3. Chou D, Tuncalp O, Firoz T, et al. Constructing maternal morbidity - towards a standard tool to measure and monitor maternal health beyond mortality. BMC Pregnancy Childbirth. 2016;16:45. doi:10.1186/s12884-015-0789-4

4. Firoz T, Chou D, von Dadelszen P, et al. Measuring maternal health: focus on maternal morbidity. Bull World Health Organ. 2013;91(10):794-796. doi:10.2471/BLT.13.117564

5. Vanderkruik RC, Tuncalp O, Chou D, Say L. Framing maternal morbidity: WHO scoping exercise. BMC Pregnancy Childbirth. 2013;13:213. doi:10.1186/1471-2393-13-213

6. Cecatti JG, Souza JP, Parpinelli MA, de Sousa MH, Amaral E. Research on severe maternal morbidities and near-misses in Brazil: what we have learned. Reprod Health Matters. 2007;15(30):125-133. doi:10.1016/S0968-8080(07)30333-9

7. World Health Organization. Evaluating the quality of care for severe pregnancy complications: the WHO near-miss approach for maternal health; 2011.

8. Goldenberg RL, Saleem S, Ali S, et al. Maternal near miss in low-resource areas. Int J Gynaecol Obstet. 2017;138(3):347-355. doi:10.1002/ ijgo. 12219

9. Reichenheim ME, Zylbersztajn F, Moraes CL, Lobato G. Severe acute obstetric morbidity (near-miss): a review of the relative use of its diagnostic indicators. Arch Gynecol Obstet. 2009;280(3):337-343. doi:10.1007/s00404-008-0891-1

10. Owolabi O, Riley T, Juma K, et al. Incidence of maternal near-miss in Kenya in 2018: findings from a nationally representative cross-sectional study in 54 referral hospitals. Sci Rep. 2020;10(1):15181. doi:10.1038/s41598-020-72144-x

11. Say L, Pattinson RC, Gulmezoglu AM. WHO systematic review of maternal morbidity and mortality: the prevalence of severe acute maternal morbidity (near miss). Reprod Health. 2004;1(1):3. doi:10.1186/1742-4755-1-3

12. Say L, Souza JP, Pattinson RC. Maternal near miss-towards a standard tool for monitoring quality of maternal health care. Best Pract Res Clin Obstet Gynaecol. 2009;23(3):287-296. doi:10.1016/j.bpobgyn.2009.01.007

13. Khan KS, Wojdyla D, Say L, Gulmezoglu AM, Van Look PF. WHO analysis of causes of maternal death: a systematic review. Lancet. 2006;367 (9516):1066-1074. doi:10.1016/S0140-6736(06)68397-9 
14. Ronsmans C, Graham WJ. Maternal mortality: who, when, where, and why. Lancet. 2006;368(9542):1189-1200. doi:10.1016/S0140-6736(06) 69380-X

15. Central Statistical Agency [Ethiopia] and ICF International. Ethiopia demographic and health survey (EDHS) 2011. Calverton, Maryland, USA: ORC Macro; 2012:93-99.

16. Central Statistical Agency (CSA) [Ethiopia] and ICF International. Ethiopia demographic and health survey 2016: key indicators report: addis Ababa, Ethiopia, and Rockville, Maryland, USA. CSA and ICF; 2016.

17. Federal Democratic Republic of Ethiopia Ministry of Health. Maternal death surveillance and response (MDSR) technical guideline. Addis Ababa, Ethiopia; 2014.

18. Woldeyes WS, Asefa D, Muleta G. Incidence and determinants of severe maternal outcome in Jimma University teaching hospital, South-West Ethiopia: a prospective cross-sectional study. BMC Pregnancy Childbirth. 2018;18(1):255. doi:10.1186/s12884-018-1879-x

19. Tura AK, Zwart J, van Roosmalen J, Stekelenburg J, van den Akker T, Scherjon S. Severe maternal outcomes in eastern Ethiopia: application of the adapted maternal near miss tool. PLoS One. 2018;13(11):e0207350. doi:10.1371/journal.pone.0207350

20. Liyew EF, Yalew AW, Afework MF, Essén B. Incidence and causes of maternal near-miss in selected hospitals of Addis Ababa, Ethiopia. PLoS One. 2017;12(6):e0179013. doi:10.1371/journal.pone.0179013

21. Kasahun AW, Wako WG. Predictors of maternal near miss among women admitted in Gurage zone hospitals, South Ethiopia, 2017: a case control study. BMC Pregnancy Childbirth. 2018;18(1):260. doi:10.1186/s12884-018-1903-1

22. Central Statistical Agency (CSA) [Ethiopia] and ICF International. The 2007 population and housing census of Ethiopia. Addis Ababa,Ethiopia; 2008.

23. Tekelab T, Chojenta C, Smith R, Loxton D. Incidence and determinants of neonatal near miss in south Ethiopia: a prospective cohort study. $B M C$ Pregnancy Childbirth. 2020;20(1):354. doi:10.1186/s12884-020-03049-w

24. Sayinzoga F, Bijlmakers L, van der Velden K, van Dillen J. Severe maternal outcomes and quality of care at district hospitals in Rwandaa multicentre prospective case-control study. BMC Pregnancy Childbirth. 2017;17(1):394. doi:10.1186/s12884-017-1581-4

25. Tunçalp Ö, Hindin MJ, Adu-Bonsaffoh K, Adanu RM. Assessment of maternal near-miss and quality of care in a hospital-based study in Accra, Ghana. Int J Gynaecol Obstet. 2013;123(1):58-63. doi:10.1016/j.ijgo.2013.06.003

26. Gebrehiwot Y, Tewolde BT. Improving maternity care in Ethiopia through facility based review of maternal deaths and near misses. Int J Gynaecol Obstet. 2014;127(S1):S29-S34. doi:10.1016/j.ijgo.2014.08.003

27. Chikadaya H, Madziyire MG, Munjanja SP. Incidence of maternal near miss in the public health sector of Harare, Zimbabwe: a prospective descriptive study. BMC Pregnancy Childbirth. 2018;18(1):458. doi:10.1186/s12884-018-2092-7

28. Ali AA, Khojali A, Okud A, Adam GK, Adam I. Maternal near-miss in a rural hospital in Sudan. BMC Pregnancy Childbirth. 2011;11:48. doi:10.1186/1471-2393-11-48

29. Geller SE, Koch AR, Garland CE, MacDonald EJ, Storey F, Lawton B. A global view of severe maternal morbidity: moving beyond maternal mortality. Reprod Health. 2018;15(Suppl 1):98. doi:10.1186/s12978-018-0527-2

30. Jayaratnam S, Burton A, Connan KF, Costa C. Maternal 'near miss' at Royal Darwin Hospital: an analysis of severe maternal morbidity at an Australian regional tertiary maternity unit. Aust N Z J Obstet Gynaecol. 2016;56(4):381-386. doi:10.1111/ajo.12436

31. Ghazivakili Z, Lotfi R, Kabir K, Norouzi Nia R, Rajabi Naeeni M. Maternal near miss approach to evaluate quality of care in Alborz Province, Iran. Midwifery. 2016;41:118-124. doi:10.1016/j.midw.2016.08.009

32. Tuncalp O, Souza JP. Maternal near-miss audits to improve quality of care. BJOG. 2014;121(Suppl 4):102-104. doi:10.1111/1471-0528.12868

33. Nyamtema AS, de Jong AB, Urassa DP, van Roosmalen J. Using audit to enhance quality of maternity care in resource limited countries: lessons learnt from rural Tanzania. BMC Pregnancy Childbirth. 2011;11:94. doi:10.1186/1471-2393-11-94

34. Kalisa R, Rulisa S, van den Akker T, van Roosmalen J. Maternal Near Miss and quality of care in a rural Rwandan hospital. BMC Pregnancy Childbirth. 2016;16(1):324. doi:10.1186/s12884-016-1119-1

35. Kassa GM, Muche AA, Berhe AK, Fekadu GA. Prevalence and determinants of anemia among pregnant women in Ethiopia; a systematic review and meta-analysis. BMC Hematol. 2017;17:17. doi:10.1186/s12878-017-0090-z

36. Lebso M, Anato A, Loha E. Prevalence of anemia and associated factors among pregnant women in Southern Ethiopia: a community based cross-sectional study. PLoS One. 2017;12(12):e0188783. doi:10.1371/journal.pone.0188783

37. Daru J, Zamora J, Fernandez-Felix BM, et al. Risk of maternal mortality in women with severe anaemia during pregnancy and post partum: a multilevel analysis. Lancet Glob Health. 2018;6(5):e548-e54. doi:10.1016/S2214-109X(18)30078-0

38. Iwuh IA, Fawcus S, Schoeman L. Maternal near-miss audit in the Metro West maternity service, Cape Town, South Africa: a retrospective observational study. $S$ Afr Med J. 2018;108(3):171-175. doi:10.7196/SAMJ.2018.v108i3.12876

39. World Health Organization. Quality of care: a process for making strategic choices in health systems; 2006.

International Journal of Women's Health

Dovepress

\section{Publish your work in this journal}

The International Journal of Women's Health is an international, peer-reviewed open-access journal publishing original research, reports, editorials, reviews and commentaries on all aspects of women's healthcare including gynecology, obstetrics, and breast cancer. The manuscript management system is completely online and includes a very quick and fair peer-review system, which is all easy to use. Visit http://www. dovepress.com/testimonials.php to read real quotes from published authors.

Submit your manuscript here: https://www.dovepress.com/international-journal-of-womens-health-journal 